Roseli maria Martins D’Elboux

Manifestações neoclássicas no Vale do Paraíba: LORENA E AS PALMEIRAS IMPERIAIS 


\section{MANifEstaÇÕES NEOCLÁSSICAS NO VALE DO PARAÍbA: LORENA E AS PALMEIRAS IMPERIAIS}

Dissertação apresentada à Faculdade de Arquitetura e Urbanismo da Universidade de São Paulo, para obtenção do título de Mestre

Área de Concentração: História e Fundamentos da Arquitetura e do Urbanismo Orientadora: Prof ${ }^{\mathrm{a}}$. Dra ${ }^{\mathrm{a}}$. Maria Lúcia B. Pinheiro 
AUTORIZO A REPRODUÇÃO E DIVULGAÇÃO TOTAL OU PARCIAL DESTE TRABALHO, POR QUALQUER MEIO CONVENCIONAL OU ELETRÔNICO, PARA FINS DE ESTUDO E PESQUISA, DESDE QUE CITADA A FONTE.

\author{
ASSINATURA: \\ E-MAIL: rdelboux@terra.com.br
}

D'Elboux, Roseli Maria Martins

D344m Manifestações neoclássicas no Vale do Paraíba: Lorena e as palmeiras imperiais / Roseli Maria Martins D'Elboux. - São Paulo, 2004.

190 p. : il.

Dissertação (Mestrado) - FAUUSP.

Orientadora: Maria Lucia Bressan Pinheiro.

1. Arquitetura neoclássica - Lorena (SP) 2. Paisagem urbana - Lorena (SP) I. Titulo 
ERRATA

Pág. $\quad$ Linha $\quad$ Onde se lê... $\quad$ Leia-se...

\begin{tabular}{|c|c|c|c|}
\hline 148b (ilustr.) & & Fig.64 & Fig.66 \\
\hline 154c (ilustr.) & & $154 b$ & $154 \mathrm{c}$ \\
\hline 161a (ilustr.) & 23 & 23 & 161 \\
\hline $68 \mathrm{~b}$ (ilustr.) & & $69 a$ & $68 b$ \\
\hline
\end{tabular}


Para Mirella e Letícia 


\section{AGRADECIMENTOS}

Quando iniciamos nossas atividades na pós-graduação, começamos também uma espécie de jornada, pela qual vamos coletando mais do que informações e dados. Vamos agregando, em paralelo com o conhecimento relativo à pesquisa, outras experiências, não de cunho científico, mas francamente humanistas: novas amizades, laços de relacionamento que nos trazem variadas contribuições, possibilitando-nos o confronto de idéias - a verdadeira troca de conhecimento que possibilita o andamento da vida acadêmica. Mas, principalmente, desempenham o importantíssimo papel de "ombro amigo", nos trazendo conforto e esperança quando nos encontramos um pouco perdidos nessa jornada.

Mais do que todos, entretanto, é o orientador que está constantemente segurando a lanterna, indicando quais os caminhos possíveis para o prosseguimento da pesquisa. Outras vezes, é a sua mão que nos impede de avançar em áreas nebulosas. Portanto, só tenho a agradecer à Prof ${ }^{a}$ Maria Lucia Bressan Pinheiro, orientadora pacientíssima, que suportou todos os meus atrasos e desvios de rota e esteve sempre me advertindo para focalizar e perseguir meus objetivos. Além da relação orientador-orientando, acredito que fomos construindo uma relação de respeito mútuo ao longo desses três anos. Agradeço, também ao professores das bancas de Qualificação e Argüição, pelas críticas e sugestões.

Em Lorena, devo especial agradecimento ao Prof. José Geraldo Evangelista, pelos seus conselhos em nosso breve encontro logo no início da pesquisa, e com os quais infelizmente não pude mais contar. Espero ter feito jus às suas expectativas e à sua memória. E a José Francisco Vidal Martins, que providenciou nosso encontro. Também não 
poderia esquecer de Dalva, do Arquivo Municipal e de Vanda, da Casa de Cultura de Lorena. Lourdes Martins tem um lugar especial no meu coração, pela acolhida carinhosa de sempre.

Jacy Ghirotti, pela gentileza da revisão das traduções. Agradecimento especial dedico a Alexandre Luís Rocha, amigo conquistado nessa jornada, com quem aprendi a ser generosa com relação ao saber. Agradeço-lhe pelo auxílio na bibliografia, pela leitura crítica de alguns trechos de minha dissertação e seus sempre úteis conselhos. A Sabrina Studart e Manoela Rufinoni, outras amizades que colhi nesse período, agradeço pelo estímulo constante.

Sem o meu amigo de todas as horas, Valter Caldana - meu irmão de coração nãoteria nem ingressado no mestrado. Por "aquela força" que sempre me dá, por seus conselhos, advertências, por sua paciência infinita com meus momentos de tensão e insegurança, muito obrigada. Agradeço a Rosa Kliass, mestra na vida profissional, com quem aprendi a importância de sempre fazer o melhor.

Agradeço, sempre, a meus pais, referência de vida e à Elza e Rose, que cuidaram de minhas meninas enquanto eu preparava esta dissertação.

E, last but not least, ao José Roberto, por muito, mas muito mesmo. 
Lá estão elas de guarda, noite e dia, imóveis como mármores. Aos raios do luar, à vista desses alvos espectros, dir-se-ia uma enfiada de colunas tebanas.

C. Ribeyrolles 
D’ELBOUX, Roseli M. M. Manifestações neoclássicas no Vale do Paraíba: Lorena e as palmeiras imperiais. 2004. xxf. Dissertação (Mestrado) - Faculdade de Arquitetura e Urbanismo, Univesidade de São Paulo, São Paulo, 2005.

A presente dissertação propõe-se a discutir a influência da linguagem neoclássica na formação da paisagem urbana das cidades valeparaibanas a partir do estabelecimento de uma elite ligada à cultura do café nessa região. Seu recorte cronológico abrange o período entre 1830 e 1890, enquanto espacialmente tem seu foco direcionado na cidade de Lorena, São Paulo, de modo a cobrir as transformações aí ocorridas desde a chegada do café até o esgotamento dessa cultura. A segunda metade do séc. XIX coloca-se como um momento importante para o seu processo de urbanização, pois companhando as transformações urbanas, surgiram e consolidaram-se exemplos paisagísticos próprios da sociedade do café: ruas arborizadas com renques de palmeiras, a demonstrar a proximidade com a Corte, a sinalizar os novos "modos afrancesados". Discute ainda, por um lado, as origens do jardim paisagista inglês implantado no Brasil nesse período, cujo expoente é Glaziou e, por outro, as razões para a adoção da palmeira imperial (Roystonea oleracea) como símbolo de nobreza e sua ligação com a linguagem neoclássica, sendo utilizada com o propósito de qualificar os logradouros públicos a fim de equipará-los aos novos edifícios que substituíam aqueles da tradição colonial.

Palavras chave: século XIX; arquitetura neoclássica; café; Vale do Paraíba; paisagem urbana 
D’ELBOUX, Roseli M. M. Neoclassical manifestation in the Paraíba's Valley: Lorena and the Royal Palm Trees. 2004. xxxp. Dissertation Title (Master of Science degree) - Faculdade de Arquitetura e Urbanismo, Univesidade de São Paulo, São Paulo, 2005 .

This essay proposes to discuss the influence of neoclassical language in the urban landscape formation of the cities in the Paraiba's Valley started with the settlement there of an elite, connected with coffee growing. Its chronological focus concerns the period between 1830 and 1890, while its spatial focus is oriented to Lorena city, estate of São Paulo, covering the transformations that occurred there, since the beginning of coffee growing until its exhaustion by the 1890 s, corresponding, not by chance, with the end of the Second Empire. The second half of XIX century is seen as a fundamental moment for the urbanization process, because following the urban transformations, specifics landscapes examples of the coffee society appeared and consolidated: streets with rows of palm trees, trying to demonstrate a proximity with the Court, signalizing the new 'Frenchified manners.' Also, the essay discusses the origins of the British landscape garden implanted in Brazil at that time, where Glaziou was the leading exponent, and the reasons why the Royal Palm Tree (Roystonea oleracea) was adopted as a symbol of nobility and its connections with the neoclassical language, being used with the aim of characterize public areas, to make them equal to the new buildings that were taking place of those within the colonial tradition.

Key-words: : 19th century; neoclassical architecture; coffe; Lorena; urban landscape 
Fig. Pág. Descrição

\begin{tabular}{lll}
\hline \hline 1 & $40 \mathrm{a}$ & As cinco ordens \\
2 & $41 \mathrm{a}$ & Representação da ordem dórica \\
3 & $47 \mathrm{a}$ & Combinaisons horizontales... \\
4 & $47 \mathrm{a}$ & Ensembles d'edifices résultants... \\
5 & $48 \mathrm{a}$ & Stereotomia \\
6 & $59 \mathrm{a}$ & Versalhes \\
7 & $65 \mathrm{a}$ & A-ha \\
8 & $65 \mathrm{a}$ & Plano do jardim de Twicknham \\
9 & $66 \mathrm{a}$ & Rousham \\
10 & $67 \mathrm{a}$ & Stourhead \\
11 & $68 \mathrm{a}$ & Regent's Street \\
12 & $68 \mathrm{~b}$ & Regent's Street - foto aérea... \\
13 & 69 & Jardim anglo-chinois \\
14 & 70 & Le Desert de Retz \\
15 & 70 & A scéne do pavilhão filosófico... \\
16 & 70 & Champs Elysées \\
17 & $71 \mathrm{a}$ & Bois de Bologne \\
18 & $71 \mathrm{a}$ & Les Promenades de Paris Bois de Bologne \\
19 & 72 & Les Promenades de Paris Parque Montsouris \\
20 & 73 & Les Promenades de Paris: grilles \\
21 & 74 & Les Promenades de Paris: Parque de Buttes-Chaumont \\
22 & $74 \mathrm{a}$ & Les Promenades de Paris: Parque de Buttes-Chaumont \\
23 & 76 & Les Promenades de Paris \\
24 & 76 & Les Promenades de Paris \\
25 & 77 & Perfil de rua \\
26 & 78 & Les Promenades de Paris: Detalhes \\
27 & 78 & Les Promenades de Paris: Candelabres \\
28 & $86 \mathrm{a}$ & Projeto de chafariz para a Rua S. Clemente \\
29 & $86 \mathrm{a}$ & Projeto de chafariz para o Largo do Benfica \\
30 & $88 \mathrm{a}$ & Projeto de remodelação do centro do Rio de Janeiro \\
31 & $90 \mathrm{a}$ & Campo de Santana \\
32 & $90 \mathrm{a}$ & Projeto de Eliseu... \\
33 & $91 \mathrm{a}$ & Porjeto de embelezamento... \\
34 & $91 \mathrm{~b}$ & Projeto de união do Palácio do Louvre ... \\
35 & $91 \mathrm{c}$ & Projeto de um palácio para o rei da Vestfália... \\
36 & $93 \mathrm{a}$ & O Passeio em 1817 \\
37 & $93 \mathrm{a}$ & Planta da reforma de Glaziou... \\
39 & $93 \mathrm{a}$ & Le Promendades des Paris. Detalhes \\
41 & $94 \mathrm{a}$ & Pavilhão brasileiro na Exposição de 1889 \\
& $97 \mathrm{a}$ & Quinta da Boa Vista \\
\hline & & \\
\hline 1 &
\end{tabular}




\begin{tabular}{|c|c|c|}
\hline 42 & $97 \mathrm{a}$ & Campo de Santana \\
\hline 43 & $106 \mathrm{a}$ & Mapa da comarca... \\
\hline 44 & $106 \mathrm{a}$ & Mapa de huã parte do novo continente... \\
\hline 45 & $106 b$ & Plano que compreende... \\
\hline 46 & $106 \mathrm{c}$ & Caminhos do Vale do Paraíba \\
\hline 47 & $111 \mathrm{a}$ & Localização das travessias do Rio Paraíba \\
\hline 48 & $116 \mathrm{a}$ & Vila da Piedade \\
\hline 49 & $122 \mathrm{a}$ & Lorena vista do leste \\
\hline 50 & $122 \mathrm{a}$ & Em Lorena \\
\hline 51 & $134 \mathrm{a}$ & Família Moreira Lima \\
\hline 52 & $136 \mathrm{a}$ & Lorena em 1830 \\
\hline 53 & $140 \mathrm{a}$ & Torreão para recepção da Princesa Isabel \\
\hline 54 & $140 \mathrm{~b}$ & Arco Triunfal... \\
\hline 55 & $140 \mathrm{~b}$ & Arc de Trionphe... \\
\hline 56 & $141 \mathrm{a}$ & Localização das figueiras \\
\hline 57 & $142 \mathrm{a}$ & Figueira da Pça. Dr. Gama Rodrigues \\
\hline 58 & $142 \mathrm{a}$ & A mesma figueira... \\
\hline 59 & $142 \mathrm{a}$ & Figueira Pça Major Rodrigues Liuz \\
\hline 60 & $143 \mathrm{a}$ & Figueira da Cabellinha, 1915 \\
\hline 61 & $143 a$ & Figueira da Cabellinha, c. 1970 \\
\hline 62 & $146 \mathrm{a}$ & Localização dos logradouros... \\
\hline 63 & $146 b$ & Ponte metálica \\
\hline 64 & $148 \mathrm{a}$ & Lorena. Jardim Público \\
\hline 65 & $148 b$ & Lorena. Jardim Público \\
\hline 66 & $148 b$ & Pça. Dr. Arnolfo de Azevedo \\
\hline 67 & $148 \mathrm{c}$ & Lorena. R. Dr. Rodrigues \\
\hline 68 & $148 \mathrm{c}$ & Lorena. R. Da Piedade \\
\hline 69 & $148 \mathrm{~d}$ & Vista aérea do centro de Lorena \\
\hline 70 & $149 \mathrm{a}$ & Va. de Lorena \\
\hline 71 & $152 \mathrm{a}$ & Duas palmeiras imperiais... \\
\hline 72 & $152 \mathrm{a}$ & Lorena às margens do Paraíba... \\
\hline 73 & $154 \mathrm{a}$ & Residência Bráulio de Castro Lima \\
\hline 74 & $154 b$ & Residência Conde de Moreira Lima. Acréscimo... \\
\hline 75 & $154 \mathrm{c}$ & Residência Conde de Moreira Lima. Detalhe... \\
\hline 76 & $154 \mathrm{c}$ & Residência Conde de Moreira Lima. Detalhe... \\
\hline 77 & $154 d$ & Residência Conde de Moreira Lima. Pilar metálico \\
\hline 78 & $154 d$ & Residência Conde de Moreira Lima. Fachada \\
\hline 79 & $155 \mathrm{a}$ & Residência Barão de Sta. Eulália \\
\hline 80 & $155 \mathrm{a}$ & Residência Barão de Sta. Eulália \\
\hline 81 & $155 b$ & Largo da Matriz \\
\hline 82 & $155 b$ & Jardim Botãnico do Rio de Janeiro \\
\hline 83 & $156 \mathrm{a}$ & Palmeiras imperiais \\
\hline 84 & $156 \mathrm{a}$ & Palmeiras imperiais \\
\hline 85 & $158 \mathrm{a}$ & Flora fluminensis \\
\hline 86 & $158 \mathrm{a}$ & Aléia de palmeiras imperiais \\
\hline
\end{tabular}


LISTA DE SÍMBOLOS, ABREVIATURAS, SIGLAS

Abrev. Significado

\begin{tabular}{ll}
\hline \hline EAV & École d'architecture de Versailles \\
ENSMP & École Nationale Supérieur des Mines de Paris \\
FAUUSP & Faculdade de Arquitetura e Urbanismo da Universidade de São Paulo \\
FBN & Fundação Biblioteca Nacional \\
IPHAN & Instituto do Patrimônio Histórico e Artístico Nacional \\
MHN & Museu Histórico Nacional \\
MNBA & Museu Nacional de Belas Artes \\
N.O. & No original \\
T.A. & Tradução da autora
\end{tabular}


INTRODUÇÃO

CAPÍTULO I

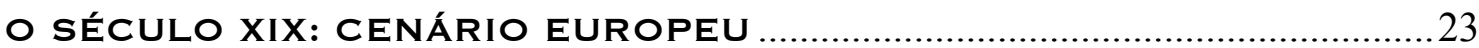

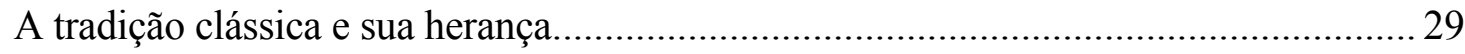

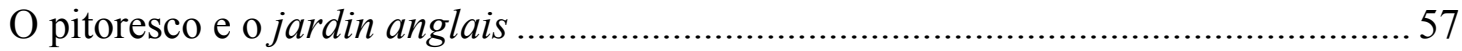

CAPÍTULO II

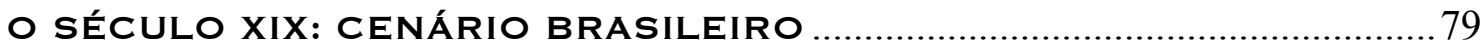

O neoclássico no Rio de Janeiro: Grandjean de Montigny .......................................... 83

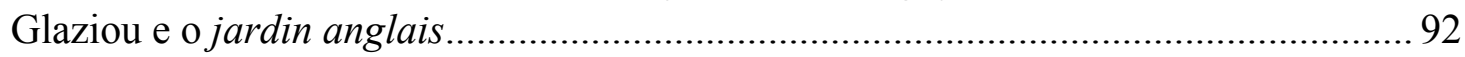

CAPÍTULO III

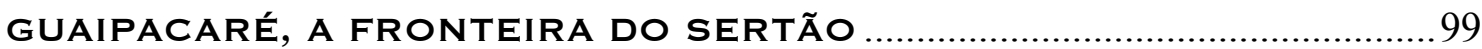

A abertura do caminho geral e a ocupação do Vale do Paraíba....................................... 99

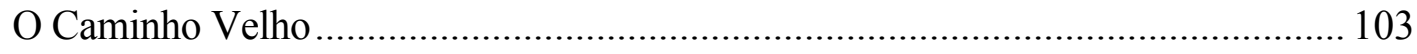

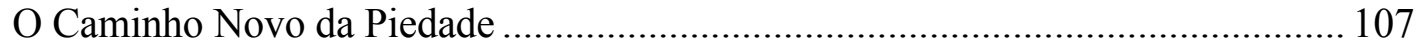

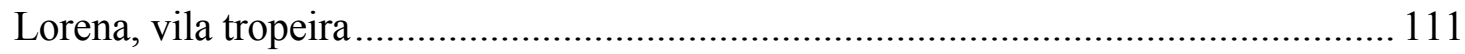

CAPÍTULO IV

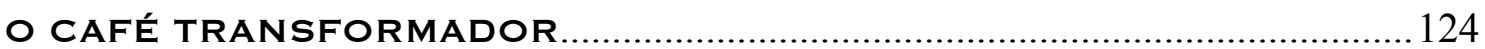

O baronato local, agente do melhoramento da cidade................................................ 129

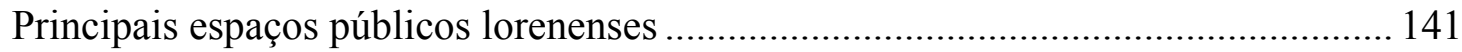

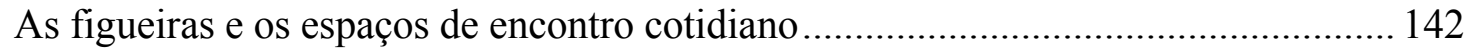

As palmeiras e os espaços de representação da elite ..................................................... 145

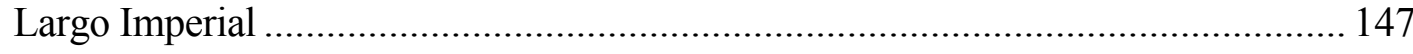

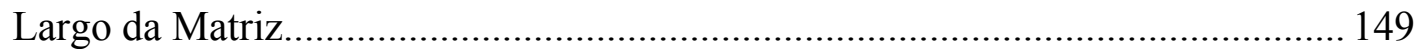

Rua Viscondessa de Castro Lima ..................................................................... 156

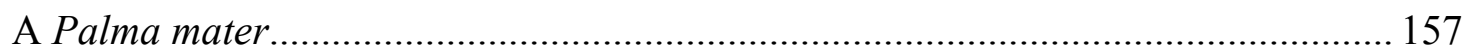

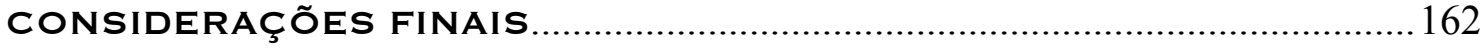

O neoclassicismo nas ruas: as palmeiras imperiais .................................................... 162

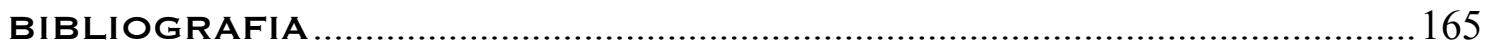

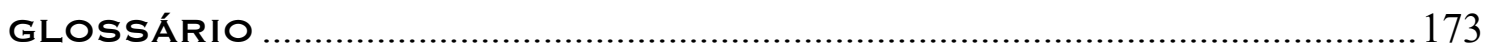

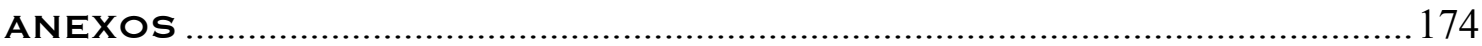


Com a presente dissertação propomo-nos a discutir a influência da linguagem neoclássica na formação da paisagem urbana das cidades vale-paraibanas a partir do estabelecimento de uma elite ligada à cultura do café nessa região.

A segunda metade do século XIX coloca-se como um momento importante para o seu processo de urbanização. Acompanhando as transformações urbanas, surgiram e consolidaramse exemplos paisagísticos próprios da sociedade do café: ruas arborizadas com renques de palmeiras, a demonstrar a proximidade com a corte, a sinalizar os novos "modos afrancesados".

O que se coloca como objetivo da pesquisa é a discussão e avaliação do processo pelo qual as elites formadas em determinado contexto assumem certos valores estéticos que a legitimam do ponto de vista cultural e venham a identificá-la no processo histórico de nossa sociedade.

O processo que nos interessa na pesquisa é a identificação das transformações ocorridas no ambiente urbano como resultado da aplicação de riquezas geradas a partir do cultivo do café no Vale do Paraíba, colocando-se como premissa que a produção do ambiente é também a produção da identidade de uma sociedade.

Espacialmente, avaliamos que a cidade de Lorena, no Vale do Paraíba, possibilita a observação dos fenômenos de transformação ambiental sobre os quais queremos nos debruçar. 
A escolha de Lorena é justificada por alguns importantes dados, que a fazem particularmente interessante, do ponto de vista histórico. A cidade tem origem bandeirista, caracterizando-se como a última fronteira do sertão na direção norte ${ }^{1}$ da Capitania de São Paulo, sendo seu núcleo original justamente o ponto de travessia do Rio Paraíba em direção ao sertão das Minas Gerais.

Descoberto o ouro, passa a ser, ainda em função da transposição do Paraíba, ponto de descanso dos tropeiros que faziam o fluxo aurífero. Torna-se entroncamento de caminhos, já que desde Lorena as tropas podiam se dirigir a São Paulo ou para o Rio de Janeiro, após vencer a Serra de Quebra-Cangalha e descer a Serra do Mar, alcançando assim os portos de Parati, Mambucaba e Ubatuba.

No final do século XVIII, é de Lorena que parte a estrada que fará a ligação terrestre entre São Paulo e a corte fluminense. No início do século XIX, chegou a constar como o município mais populoso da província paulista, superando a própria capital.

Essa situação privilegiada vai dar espaço para outras possibilidades, ou seja, na geopolítica da colônia, torna-se um centro importante de articulação entre três províncias - São Paulo, Rio de Janeiro e Minas Gerais - de sorte que será o palco das lutas da Revolução Liberal de 1842 , rebeldia que lhe custou a anexação à província do Rio de Janeiro por quatorze anos (1842-1856).

Mais tarde, já no século XX, novamente ganha importância na logística militar do deslocamento de tropas constitucionalistas, durante a Revolução de 1932.

\footnotetext{
${ }^{1} \mathrm{Na}$ verdade leste, mas à época a região era assim designada.
} 
Outra justificativa para a escolha da cidade de Lorena diz respeito à sua relevância frente ao conjunto do patrimônio urbano vale-paraibano, devido a existência, na cidade, de algumas obras de Ramos de Azevedo, o mais famoso arquiteto paulista do período: a Igreja Matriz de Nossa Senhora da Piedade, e algumas intervenções ou reformas que lhe são atribuídas, como a do Solar dos Azevedo, localizado na mesma praça onde se ergue a Matriz, a igreja do Rosário e a capela de São Miguel das Almas, mausoléu da família Moreira Lima no cemitério municipal.

O objeto de nossa dissertação é a relação que se estabelece entre a burguesia do café e os espaços públicos da área urbana, onde essa mesma burguesia está estabelecida desde meados do século XIX correspondendo, atualmente, ao que poderíamos considerar como o centro histórico da cidade de Lorena. Do relacionamento dessa burguesia, surgida em função da cultura cafeeira com o núcleo inicial da cidade, várias ações transformadoras irão tomar corpo, notadamente no último quartel do século.

De fato, da relação entre a burguesia local e o espaço de representação que lhe é tão caro - os logradouros públicos lorenenses - é que podemos extrair o verdadeiro sentido deste trabalho, qual seja, o exame do que significou o neoclássico nesse pequeno universo valeparaibano.

A essa época, o café já não apresentava grande produtividade na região e muitos dos fazendeiros locais haviam adquirido terras e migrado para o então chamado Oeste Paulista, o que faz supor em um primeiro momento, que os barões lorenenses não dispunham de capital para acompanhar a marcha do café ou que fossem caipiras, pouco cosmopolitas e ligados à sua terra natal (LEMOS, 1987) e não estivessem dispostos a tamanha mudança. 
A nosso ver, a idéia de uma possível falência do baronato local não procede, pois os maiores investimentos nos espaços públicos se deram justamente nessa época e várias ações foram literalmente pagas com o dinheiro dessas pessoas.

Por outro lado, também não procede imputar-lhes a pecha de "caipiras", pois suas ações visavam à modernização da cidade, tanto no que diz respeito a obras de infraestrutura quanto à questão do embelezamento dos logradouros lorenenses.

Parece-nos que as razões para essa permanência seriam outras. Por exemplo, a manutenção ou a complementação de sua fortuna advinda da produção agrícola com o exercício da atividade financeira, emprestando dinheiro a juros para a execução das tais obras, inclusive para a Câmara Municipal, como atestam algumas das Atas as quais tivemos acesso, como por exemplo, a “Acta de 22 de fevereiro de 1884 - $3^{\mathrm{a}}$ sessão ordinaria":

O mesmo Snr Presidente comunicou que a vista da urgencia do cazo, autorizou um emprestimo até a quantia de dusentos mil, para com o Snr. B. de Moreira Lima para melhoramento da Praça d'este mesmo nome e pedia approvação d'esta Camara, cuja quantia sera paga em 31 de julho.

Assim, colocam-se como beneméritos, mas não o são de fato, afirmando-se na verdade como bons financistas, extraindo lucros dessa atividade. Mas isso são hipóteses que ainda devem ser investigadas em outros trabalhos, de natureza diversa desta dissertação.

Encaminhamo-nos em outra direção: discutiremos questões referentes à linguagem arquitetônica adotada para essas transformações que, se num primeiro nível refletem o gosto da época, em um segundo nível, mais aprofundado, sinalizam as transformações sócioculturais que estavam em curso no período.

Assim, o recorte cronológico da presente dissertação, de acordo com nosso interesse, está fixado dentro do arco de tempo que se inicia em 1832, ano em que foi inaugurada a primeira ponte para a travessia do Rio Paraíba, quando cessou o trabalho das barcas, e que 
fixa, portanto, o início das transformações urbanas, já que para sua construção houve a necessidade da desapropriação de terrenos, demolição de casas e a abertura de uma rua, ligando a ponte ao Largo da Matriz. Foi esta a primeira intervenção, digamos, de caráter modernizador, em decorrência do surto cafeeiro.

Para o fechamento do arco temporal considerado, fixamos o ano de 1890 , quando foi inaugurada a nova Matriz, projetada por Ramos de Azevedo, fato que assinala o fim de uma época, pelo significado de sua contratação, que vem corroborar a importância da cidade de São Paulo naquele momento, como novo pólo econômico e político.

A linguagem adotada por Ramos de Azevedo para a Matriz, coloca-a lado a lado com as obras que vinham sendo realizadas na capital paulista, de sentido francamente eclético. Mas ao contrário dos chalés de gosto afrancesado que também estavam sendo levantados em Lorena, as obras de Ramos vinham revestidas de uma espécie de "sisudez" necessária para a representação da nova burguesia.

Se em 1877 foi inaugurada a ligação ferroviária São Paulo - Rio de Janeiro, com a inauguração da estação de Cachoeira Paulista, o que faria supor uma concretização da ligação já antiga entre Lorena e Rio de Janeiro, desde 1867 a Ferrovia Santos-Jundiaí já estava operando e promovendo o escoamento do café pelo porto santista.

Assim, a influência de São Paulo só cresceu nestes dez anos que separam as duas inaugurações e a contratação do arquiteto paulista, em detrimento do francês Peyrouton, estabelecido no Rio de Janeiro - que executara o projeto do Santuário de São Benedito em Lorena e do Palacete do Conde da Palmeira em Pindamonhangaba e inclusive chegou a desenvolver um projeto para a Matriz lorenense - reforça essa polarização e reitera a aproximação entre os lorenenses e a capital paulista. 
Portanto, o problema a que nos propomos a enfrentar diz respeito à definição do que significou o estilo neoclássico para essa porção do Vale do Paraíba - exemplificada por Lorena - e qual a abrangência desse modelo no próprio fato urbano lorenense.

O período escolhido e os contextos sócioculturais a ele relacionados já foram objeto de estudo de diversos autores, porém com o enfoque voltado para a produção dos espaços edificados. O que se pretende é, inclusive, a partir dos trabalhos anteriores, levar a análise um pouco mais adiante, à paisagem urbana que se organiza concomitantemente à produção dos edifícios.

Alguns estudos têm colocado que o neoclássico, no rastro do café, não se expandiu além dos limites da província do Rio de Janeiro e que este movimento teve poucos ecos no Vale do Paraíba, em sua porção paulista.

Acreditamos que, quanto à arquitetura propriamente dita, tal fato é verdadeiro. No entanto, com relação aos espaços públicos e áreas verdes criadas a partir do enriquecimento daquelas sociedades, a configuração clássica está presente tanto no desenho quanto no tratamento paisagístico que lhe são dispensados.

Surgem, então, algumas questões as quais nos propomos a responder: Que neoclássico é esse? Como se manifestou, de fato, o neoclássico no Vale do Paraíba? Qual a sua amplitude?

Se a configuração inicial de tais espaços, na maioria das vezes é o da tradição colonial paulista, no sentido de que não foram concebidos por um projeto preciso, sendo fruto em grande parte das rotas e caminhos para o sertão, posteriormente, principalmente a partir de meados do século XIX, serão esses espaços a base para a nova concepção de cidade que se importa da corte e, por extensão, da Europa. 
Assim, no Capítulo I, abordaremos a questão do neoclássico, suas origens e manifestações na Europa, principalmente na França, onde os ideais revolucionários produzem, no meio arquitetônico, as escolas chamadas visionária e racionalista.

Inicia-se, nesse período, a discussão sobre a validade do uso das formas tradicionais dentro do contexto cada vez mais industrializado. Na Inglaterra, a expressão local que mais contribui para o período é o surgimento do chamado jardim paisagista, que transposto à França, origina o jardin anglais.

No Capítulo II, trataremos da inserção da linguagem clássica dentro do cenário brasileiro àquela época e suas implicações, diretas e indiretas, como a questão da regulamentação e da ordenação da aparência das cidades.da importânciaa partir da chegada da corte portuguesa ao Rio de Janeiro, em 1808.

Também, sob a influência da chegada da corte, será vista a atuação de Grandjean de Montigny do ponto de vista das intervenções urbanas, que abrem caminho para os trabalhos de Glaziou, na segunda metade do século.

No Capítulo III, será discutida a formação ou a origem dos espaços públicos na Lorena tropeira, ainda Villa da Piedade, passagem obrigatória para as tropas que, dirigindo-se ou provenientes de São Paulo ou do litoral, seguiam para as Minas Gerais pelo Caminho Real, e deveriam transpor o Rio Paraíba naquela localidade.

Aliás, é devido à parada para a travessia do rio que vai ser erguida a capela da Piedade de Guaypacaré, ermida fundadora da cidade. Dos caminhos tropeiros, em direção ao Rio de Janeiro ou à vila de Guaratinguetá, serão definidos os principais eixos da cidade, ainda hoje 
reconhecíveis no traçado urbano lorenense e de onde evoluíram os três espaços públicos que serão examinados neste trabalho.

No Capítulo IV, abordaremos a chegada do café ao Vale do Paraíba paulista e o aparecimento da elite cafeeira dentro de um quadro rural tradicional paulista, ligado tanto à produção do açúcar pela exploração canavieira como pela agricultura e pecuária de subsistência que deram suporte ao ciclo do ouro em Minas ou mesmo pelo comércio, apoiado na atividade tropeira.

No rastro da mudança da base produtiva dar-se-ão mudanças nas relações sociais e conseqüentemente, na vida e aparência das cidades. Procuraremos demonstrar como o baronato local agiu, no sentido de melhorar não só as condições de vida dentro de suas casas, como também transformar a vida da cidade em geral, pelo financiamento de melhoramentos, quer fossem em termos de infra-estrutura, quer em termos de ornamentação.

Para tanto, a transformação dos espaços públicos passava pela negação do modelo colonial, das origens. Era preciso estar mais próximo da corte e dos hábitos cortesãos, intenção esta refletida pelo tratamento dispensado às praças da Imperatriz, da Matriz e à Rua Direita (atuais Dr. Arnolfo de Azevedo, Praça Baronesa de Santa Eulália e Rua Viscondessa de Castro Lima, mais popularmente conhecida como Rua das Palmeiras), que ostentavam renques de palmeiras imperiais, a exemplo dos existentes no Jardim Botânico do Rio de Janeiro e em vários logradouros daquela cidade.

Da adoção dessa linguagem solene e transbordante de monumentalidade para os espaços públicos, vai se moldar a identidade da cidade, transformando-os em, além de cartões postais de Lorena, testemunhos de uma época de riqueza e ostentação. 
Ainda discutiremos o esforço de aclimatação de espécies exóticas para uma produção rentável, pela necessidade de geração de renda para o próprio sustento da corte. Naquela época, a questão da exploração de essências nativas ou exóticas era uma possibilidade de reverter o quadro econômico que se instalara em Portugal, dentro do âmbito das colônias portuguesas, tanto no Brasil como na África. Além disso, Portugal visava também à exclusividade do cultivo dessas espécies.

Surgem então, algumas iniciativas, como a criação dos hortos botânicos, sendo o mais significativo deles o Jardim Botânico do Rio de Janeiro. Nesse quadro, ocorrem as primeiras experiências com o cultivo do café. Surge também, associada à linguagem neoclássica da arquitetura, sua contrapartida para os jardins, com a adoção da palmeira imperial (Roystonea oleracea) como elemento paisagístico representativo daquele momento.

Quanto aos aspectos metodológicos, primeiramente, foi realizada pesquisa bibliográfica pela qual, em se contemplando o período e a área estudada, procuramos uma aproximação ao objeto de estudo.

Paralelamente, realizamos pesquisa iconográfica e fotográfica relativa ao objeto de estudo, que, junto com as informações obtidas da bibliografia, subsidiaram a definição do recorte cronológico-espacial da pesquisa.

Em seguida, foram realizadas visitas à cidade de Lorena, ao seu Arquivo Municipal e também ao Arquivo do Estado, em São Paulo.

Do exame dos conteúdos das informações, partimos para sua análise propriamente dita, instrumentados pelo método histórico, escolhido para a busca dos objetivos. 
Há, finalmente, uma importante observação a ser feita em relação aos limites da presente dissertação, pois o tema é bastante amplo e controverso, principalmente no tocante à questão da conceituação da produção arquitetônica no período. Nossa proposta não se esgota neste momento, ao contrário, abre um leque de possibilidades de pesquisa em relação à temática que deverão ser exploradas adiante. 